\title{
DESIGNING THE NEW BACKHAUL FOR 5G HETEROGENEOUS NETWORK BASED ON CONVERGED OPTICAL INFRASTRUCTURE
}

\author{
Taras MAKSYMYUK, Olena KRASKO, Maryan KYRYK, Vasyl ROMANCHUK, Roman KOLODIY \\ Department of Telecommunications, Institute of Telecommunications, Radio Electronics and Electronic Engineering, Lviv \\ Polytechnic National University, Bandery 12, 79013 Lviv, Ukraine, Tel.: +380 633299 117, E-mail: taras.maksymyuk@gmail.com, \\ krasko.lena@gmail.com,mkyryk@gmail.com,romanchuk@lp.edu.ua, romankolodij@ukr.net
}

\begin{abstract}
In this paper, a new flexible backhaul design is proposed based on the time-frequency resource grid. The advantage of proposed approach is in the fine granularity bandwidth allocation. Proposed approach allows tunneling of Cloud-RAN modulated radio signals between baseband processing unit and remote radio head within the same resource blocks. In addition, new handover machanism has been introduced to reduce the handover overhead in the backhaul network. The main idea of the proposed handover mechanism is in multicast data transmission to both involved eNodeBs by joint assignment of the resource elements for multiple cells during handover that allows to decrease the amount of backhaul traffic over X2 interface by $20 \%$.
\end{abstract}

Keywords: 5G, optical backhaul, OLT, ONU, handover, C-RAN

\section{INTRODUCTION}

Modern cellular networks are rapidly evolving towards $5 \mathrm{G}$ paradigm. $5 \mathrm{G}$ imposes new challenges regarding significant improvement of user experience and overall network capacity increasing by thousand times [1], [2]. Upcoming $5 \mathrm{G}$ era enables more diverse use cases and applications including Internet of Things, tactile internet, industry 4.0, etc. [3] [4].

Therefore, emerging systems will need to be agile and flexible enough in order to support the diversity of applications without increasing the network management complexity [5]. Since different services are targeting different KPIs (Key Performance Indicators), the, network has to be able to allbcate resources on the run and based on real time information.

To ensure such a flexibility of network infrastructure new concepts for network management are emerging such as software defined networks (SDN) and network functions virtualization (NFV). SDN is the concept that enables remote programming of network nodes to apply the needed changes in the network configuration [6]. SDN has been proved as an effective solution for both fixed and wireless systems to manage the quality of experience for end users. To simplify the network softwarization, NFV technology is designed to provide the end-to-end abstraction of the network resources for SDN controller.

In this article, we completely rethink the design of the network infrastructure to eliminate all bottlenecks in the pipeline between service providers and end users. We propose new converged access network that encompasses both optical backhaul and wireless access segments. Proposed network infrastructure is designed to be agnostic to radio access technologies (RATs) that allows integration of existing as well as the emerging RATs.

This paper is organized as follows. Section 2 describes the proposed design for converged network infrastructure. Section 3 provides simulation results of the network performance. Section 4 concludes the paper.

\section{ARCHITECTURE OF THE CONVERGED OPTI- CAL NETWORK}

\subsection{MAC layer design for converged optical backhaul}

Given the high requirements to the capacity in the $5 \mathrm{G}$ networks, the design paradigm is moved towards ultradense cells deployment with extremely high frequency reuse and system spectral efficiency. In addition, 5G is much more heterogeneous in terms of architecture and radio access technologies, comparing to existing LTE networks. Due to the denser infrastructure of 5G network, handovers become more frequent resulting in high fluctuations traffic of load in each cell [7]. This in turn, results in the load-balancing problem between neighbor cells and their corresponding backhaul links [8] [9]. Using separate wavelengths for each small cell, we can maintain enough throughput for optical backhaul. But, in this case bandwidth utilization is quite low, because most of the time traffic demand will be less than the capacity provided by backhaul. Especially, this problem occurs when neighbor cells have significantly different traffic load. This is a typical situation in the urban scenario. In this case, one backhaul channel is underutilized, while another has more packets in the queue than it can process with acceptable delay. Force handovers from the overloaded cell to any neighbor cell allows to solve the problem, by jeopardizing the quality of wireless channels. However, this is not a good option because it will lead to the worse users experience. We propose a new architecture for optical backhaul based on the next generation passive optical network (NG-PON) [10]. Our proposal is aimed to simplify traffic steering and load balancing in highly heterogeneous environment of 5G mobile network. In order to meet the new paradigm of 5G heterogeneous network design, we improve the network design by introducing a modified MAC layer [11]. The main idea of the proposed model is to split the entire bandwidth into resource blocks, which occupy 8 time slots and 8 carriers in frequency domain. Carriers separation is in frequency domain is $200 \mathrm{GHz}$ that is equal to $1.6 \mathrm{~nm}$ interval between wavelengths in a single optical fiber. Time slot has duration of 15 us that allows fitting resource block into the 125 us 
time frame of 10 GEPON. Proposed MAC layer can allocate any throughput for the small cell in a range between $1.25 \mathrm{Gbit} / \mathrm{s}$ and $80 \mathrm{Gbit} / \mathrm{s}$. For cells with very high traffic load, it is also possible to aggregate 4 resource blocks in frequency domain, providing the total capacity of $320 \mathrm{Gbit} / \mathrm{s}$ within 32 wavelengths.

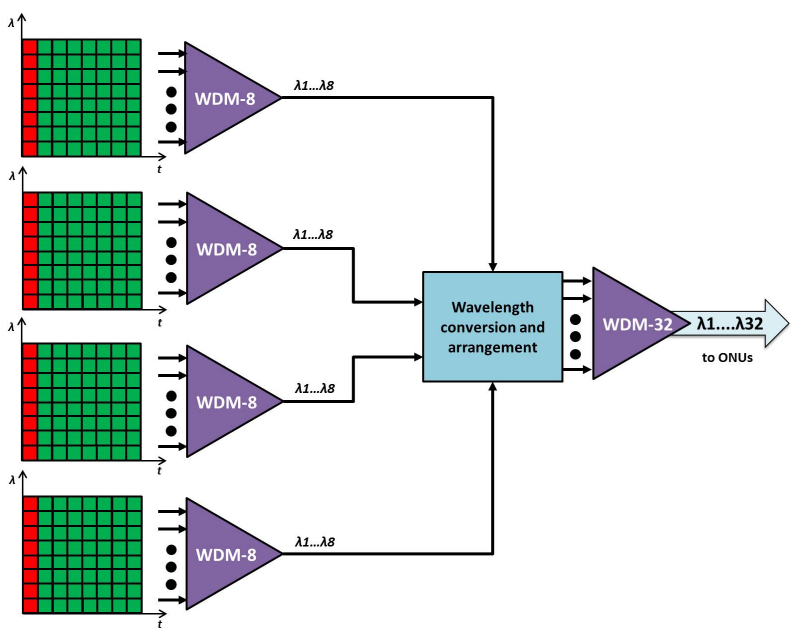

Fig. 1 Aggregation of resource blocks to provide the higher network capacity

Originally the idea of time-frequency resources allocation comes from wireless networks, such as LTE [12]. Since proposed MAC layer of optical network backhaul has similar structure to time-frequency grid of LTE network, it can be also integrated with wireless backhaul solutions for $5 \mathrm{G}$ small cells. The main advantages of the proposed MAC layer are that it allows to improve the performance of carrier aggregation, coordinated multipoint and handover.

\subsection{Analysis of cell traffic and backhaul capacity de- mand}

Backhaul capacity demands are dependent on the types of service, which dominates in the mobile network. In GSM network voice services require continuous guaranteed bit rate. Therefore, required backhaul capacity increases proportionally to the number of users. However, in current LTE and future $5 \mathrm{G}$ networks situation is very different because most of users are using packet data instead of voice calls. In addition, traffic in the cells is directly related to the SINR (signal-plus-interference-noise ratio), experienced by the users and the number of users themselves. Given 15 different CQI (channel quality indicator) values, the spectral efficiency of the wireless channels can vary from 0.15 $\mathrm{bps} / \mathrm{Hz}$ to $5.55 \mathrm{bps} / \mathrm{Hz}$, which means that total traffic in one cell, oscillates in the high range. Moreover, the amount of signaling data in wireless channels is getting higher when number of users increases. This leads to a very interesting conclusion that backhaul traffic decreases proportionally with the increasing of the number of users. Taking into account that one LTE user with CQI 15 and the lowest signaling overhead can occupy the entire capacity of the cell, we can prove that the number of users is inversely proportional to the capacity demand for backhaul. Additional factor, considered in the proposed model is the handover execution procedure via $\mathrm{X} 2$ logical interface, which triggers up to $10 \%$ of additional backhaul traffic. The signaling data via S1 logical interface and packet tunneling over the transport layer are also included in the model with another $15 \%$ of the backhaul overhead. To simplify or model, we assume that spectrum splits equally among all active subscribers. In this case the total cell throughput can be calculated according to the following equation:

$C_{\text {cell }}=\sum_{i=1}^{N} \frac{1}{N} \cdot W \cdot \operatorname{Seff}_{i}$

where $N$ is the number of users, $W$ is the total spectrum available for the cell, $\operatorname{Seff} f_{i}$ is the spectral efficiency of $i$ th user. Then, lets assume that uplink and downlink cell capacity are equal. The minimum allowed capacity of the backhaul network in downlink can be estimated based on the following equation:

$C_{\text {backhaul DL }}=\left\lceil\frac{k_{X 2} \cdot k_{t} \cdot{ }_{\text {cell }}}{O N U \text { min }}\right\rceil \cdot C_{O N U \text { min }}$

where $k_{X 2}$ is the handover coefficient (usually in a range from 1.05 to 1.2 ), $k_{t}$ is the packet tunneling overhead coefficient (usually around 1.1), $C_{O N U \text { min }}$ is the throughput granularity (1.25 Gbps). The minimum allowed capacity of the backhaul network in uplink can be estimated based on the following equation:

$C_{\text {backhaul UL }}=\left\lceil\frac{k_{X 2} \cdot \text { cell }}{\text { ONU min }}\right\rceil \cdot C_{O N U \text { min }}$

\subsection{Integration of the Cloud Radio Access Networks into converged optical infrastructure}

Cloud Radio Access Network (CRAN) was introduced as the one of possible candidates to provide $5 \mathrm{G}$ capabilities. The cloud-based architecture allows to improve the spectral and energy efficiency of the mobile network. In C-RAN, the conventional cellular base station is decoupled into two entities: baseband processing unit (BBU) and remote radio head (RRH) [13]. The responsibilities of BBU are to provide necessary signal processing, functionalities of physical, MAC, and network layer, i.e. encoding, modulation, etc. RRH is a simple transceiver without any processing capabilities. The most interesting feature of CRAN is the transmission of modulated waveforms via optical fiber link, namely fronthaul. Fronthaul interconnects the BBU and RRH, and provides transparent tunneling of radiosignals. Usually BBUs are clustered together in one big data center, and RRHs are distributed over the target coverage area. Such architecture allows to improve the flexibility of resource sharing, rapid deployment, and centralized network management. The architectural overview of the proposed converged optical network infrastructure with modified MAC layers is presented in Fig. 2. 


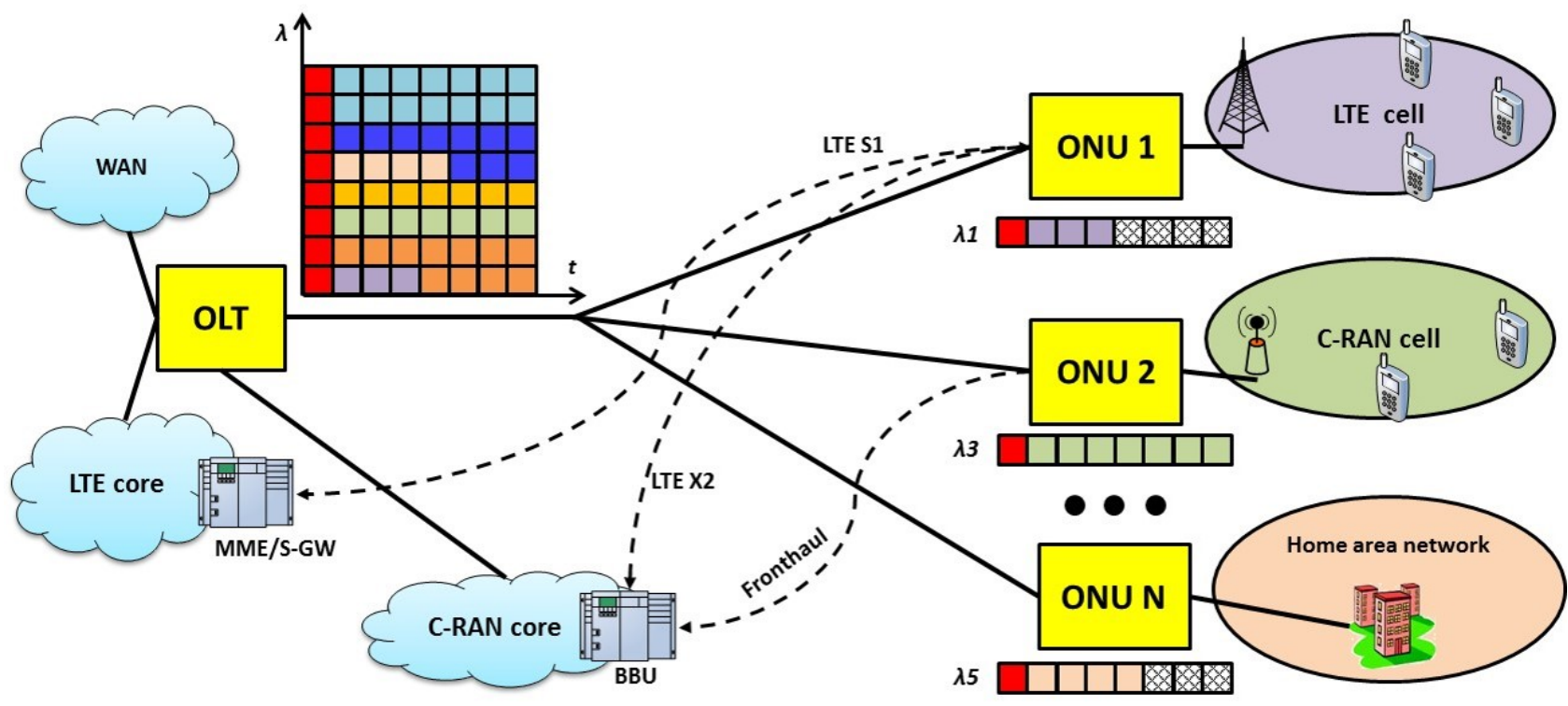

Fig. 2 Architectural overview of the proposed converged optical network infrastructure with modified MAC layers

The novelty of this model is that it allows tunneling of radio signals between baseband processing unit and remote radio head over the optical network [14]. This provides more flexibility of integration the Cloud-RAN and LTE mobile networks into converged infrastructure. As shown in Fig. 2, in our model, fronhtaul network is integrated together with other optical channels, but have different resource allocation principle. If fronthaul is integrated within the same MAC layer, it occupies the wavelengths within time-frequency resource grid but does not follow the same resources granularity. In order to support effective transmission of modulated radio signals, OLT (Optical Line Terminal) provides exclusive rights to specific wavelengths for BBU according to current demand, so that it will be transmitted in parallel with conventional LTE backhaul.

\subsection{Improved handover mechanism based on the pro- posed $5 \mathrm{G}$ backhaul architecture}

In order to reduce the amount of traffic overhead generated by handovers, we propose an improved handover mechanism among neighbor small cells. Instead of conventional data forwarding between involved cells in existing backhaul networks, we propose the multicast data transmission to several cells simultaneously by simple association of corresponding resource elements for home eNodeB and target eNodeB. When mobility management entity (MME) receives a handover request, it tells OLT to allocate the same resource elements in the resource block for multicast transmission and sends the acknowledgement to the both eNodeBs (Fig. 3).

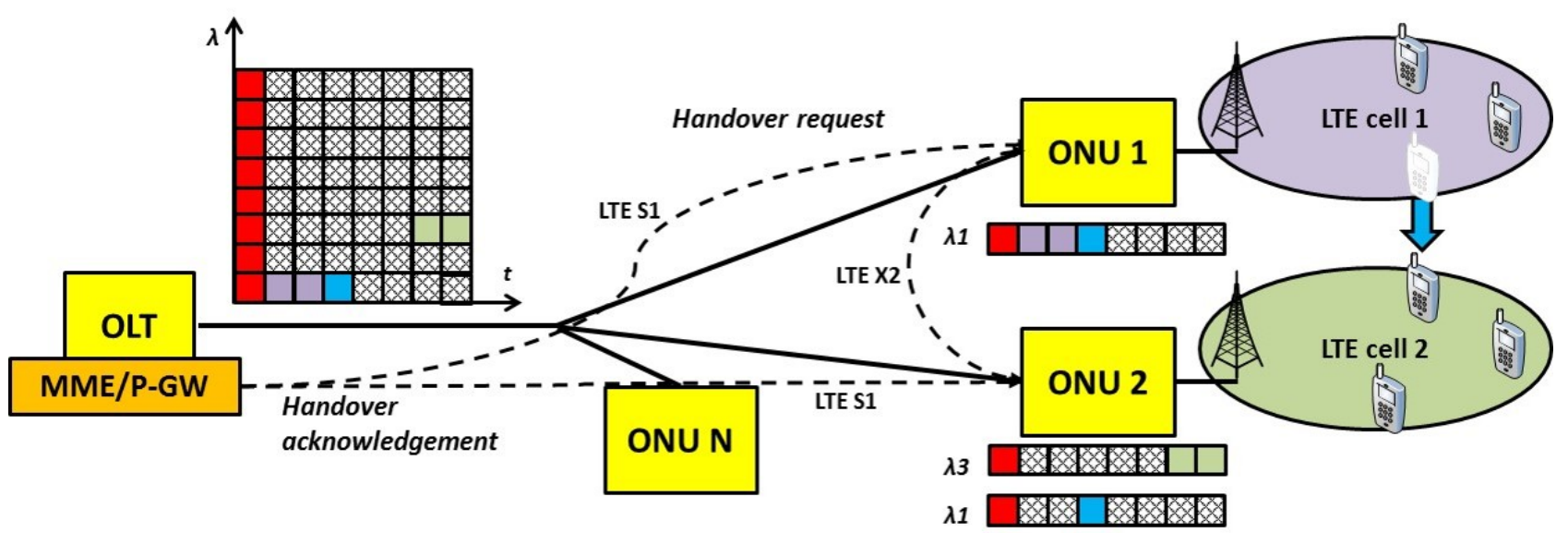

Fig. 3 Multicast data transmission in 5G backhaul during handover execution 
Thus, it is not necessary to transmit data from home eNodeB to the OLT and then forward these data from OLT to the target eNodeB during handover execution, because necessary data are known in advance in the target eNodeB Hence, we can modify the equations (2) and (3) as following:

$C_{\text {backhaul UL }}=\left\lceil\frac{C_{\text {cell }}}{O N U \text { min }}\right\rceil \cdot C_{O N U \text { min }}$

$C_{\text {backhaul DL }}=\left\lceil\frac{k_{t} \cdot C_{c e l l}}{O N U \text { min }}\right\rceil \cdot C_{O N U \text { min }}$

The sequence of the proposed handover execution algorithm is explained below. 1. The home eNodeB sends a request to the MME via the $\mathrm{S} 1$ interface. 2. MME determines the target base station and informs both involved stations about handover acknowledgement. 3. If both stations are served by the same OLT, the same resource elements are allocated for both eNodeBs in the resource block. 4. Target eNodeB received the same data as the home eNodeB, so it is not necessary to forward these data again between involved cells through OLT.

\section{SIMULATION RESULTS AND DISCUSSION}

To prove the theoretical expectations we have conducted the simulations of the backhaul capacity for two cases: existing handover mechanism and proposed handover mechanism with multicast data transmission. Results are shown in Fig. 4.

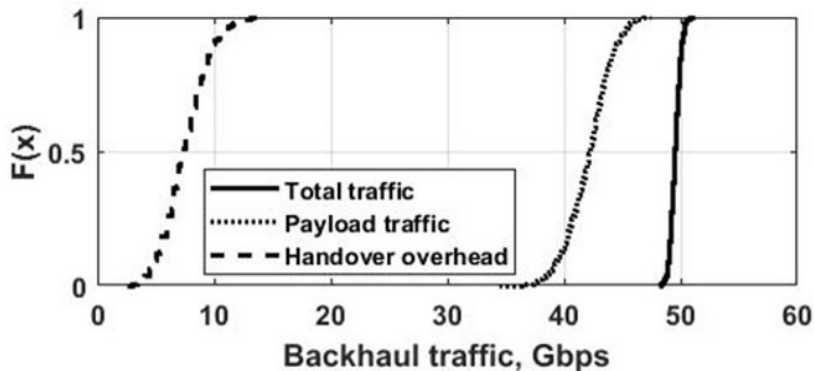

a)

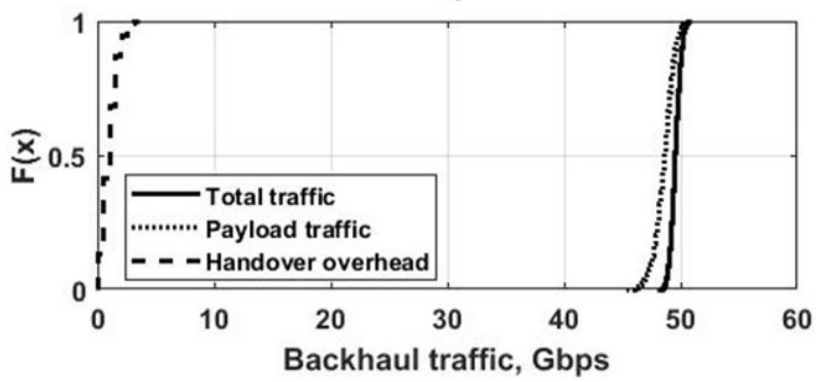

b)

Fig. 4 Simulation results of the backhaul capacity

Simulation results show that in the case of conventional handover algorithm, traffic overhead is 3 and 12 Gbps (Fig. 4a). Proposed handover algorithm decreases the amount of handover overhead to 1-3 Gbps, while increasing the payload traffic by $5-10$ Gbps.

\section{CONCLUSIONS}

In this paper, a new approach for $5 \mathrm{G}$ backhaul design is proposed based on the converged optical infrastructure. The main novelty of the proposed approach is in the timefrequency resource grid. Based on the proposed backhaul, we have designed a new handover mechanism to decrease the amount of overhead during handover execution. Simulation results show the advantage of the proposed solution over the existing ones.

\section{REFERENCES}

[1] MAKSYMYUK, T. - BRYCH, M. - PELISHOK, V.: Stochastic Geometry Models for 5G Heterogeneous Mobile Networks, Smart Computing Review, Vol. 5, No. 2, 2015, pp. 89-101.

[2] MAKSYMYUK, T. - BRYCH, M. - STRYKHALYUK, I. - JO, M.: Fractal modeling for multi-tier heterogeneous networks with ultra-high capacity demands, Smart Computing Review, Vol. 5, No. 4, 2015, pp. 346-355.

[3] MAKSYMYUK, T. - DUMYCH, S. - BRYCH, M. - SATRIA, D. - JO, M.: An IoT based monitoring framework for software defined $5 \mathrm{G}$ mobile networks, ACM International Conference on Ubiquitous Information Management and Communication (IMCOM'2017), Beppu, Japan, January, 2017, article 105.

[4] DOHLER, M. - MAHMOODI, T. - LEMA, M. - CONDOLUCI, M. - SARDIS, F. - ANTONAKOGLOU, K. - AGHVAMI, H.: Internet of Skills, where Robotics meets AI, 5G and the Tactile Internet, IEEE European Conference on Networks and Communications (EuCNC'2017), 2017, pp. 1-5.

[5] KLYMASH, M. - LAVRIV, O. - MAKSYMYUK, T. - BESHLEY, M.: State of the art and further development of information and communication systems, IEEE International Conference on Radio Electronics and Info Communications (UkrMiCo'2016), Kiev, 2016, pp. 1-6.

[6] MAKSYMYUK, T. - DUMYCH, S. - KRASKO, O. - JO, M.: Software defined optical switching for cloud computing transport systems, ACM International Conference on Ubiquitous Information Management and Communication (IMCOM'2015), Bali, Indonesia, January, 2015, article 46.

[7] MAKSYMYUK, T. - KLYMASH, M. - JO, M. Deployment strategies and standardization perspectives for $5 \mathrm{G}$ mobile networks, IEEE International Conference on Modern Problems of Radio Engineering. Telecommunications and Computer Science (TCSET'2016), Lviv-Slavske, Ukraine, February, 2016, pp. 953-956.

[8] DUMYCH, S. - MAKSYMYUK, T. - GUSKOV, P.: Simulation of burst aggregation and signalling schemes for optical burst switched networks, International Conference on Computer Science and Engineering, Lviv, Ukraine, November, 2013, pp. 40-41. 
[9] DUMYCH, S.: Study on traffic aggregation algorithms for edge nodes of optical burst switching network, IEEE International Conference on Modern Problems of Radio Engineering. Telecommunications and Computer Science (TCSET'2016), Lviv-Slavske, Ukraine, February, 2016, pp. 947-949.

[10] ZHANG, J. - COLLINGS, I. - CHEN, C. - ROULLET, L. - LUO, L. - HO, S. - YUAN, J.: Evolving Small-Cell Communications towards Mobile-overFTTx Networks, IEEE Communications Magazine, Vol. 51, No. 12, 2013, pp. 92-101.

[11] MAKSYMYUK, T. - DUMYCH, S. - KRASKO, O. - KAIDAN, M. - STRYKHALYUK, B.: Study and Development of Next-Generation Optical Networks, Smart Computing Review, Vol. 4, No. 6, 2014, pp. 470-480.

[12] JO, M. - MAKSYMYUK, T. - KYRYK, M. HAN, L.: Cognitive radio approach for LTE deployment, IEEE International Conference on the Ith International Conference Perspective Technologies and Methods in MEMS Design (MEMSTECH'2013), 2013, pp. 63-64.

[13] JO, M. - MAKSYMYUK, T. - STRYKHALYUK, B. - CHO, C.: Device-to-device-based heterogeneous radio access network architecture for mobile cloud computing, IEEE Wireless Communications, Vol. 22, No. 3, 2015, pp. 50-58.

[14] DUMYCH, S. - MAKSYMYUK, T. - KRASKO, O. - GUSKOV, P.: The virtual channel parameters calculation in all-optical network, IEEE International Conference on Experience of Designing and Application of CAD Systems in Microelectronics (CADSM'2013), Lviv-Polyana, Ukraine, 2015, p. 88.

Received September 9, 2017, accepted December 20, 2017

\section{BIOGRAPHIES}

Taras Maksymyuk is now an Assistant Professor of Telecommunications Department, Lviv Polytechnic National University, Lviv, Ukraine. He received his $\mathrm{PhD}$ degree in telecommunication systems and networks in 2015, M.S. degree in information communication networks in 2011, and BA degree in telecommunications in 2010, all from Lviv Polytechnic National University. He did his postdoc fellowship in Internet of Things and Cognitive Networks Lab, Korea University under supervision of Prof. Minho Jo. He was awarded as the Best Young Scientist of Lviv Polytechnic National University in 2015. He received the Lviv State Administration prize for outstanding scientific achievements and contribution in 2016 and Lviv Metropolitan Prize for best scientists in 2017. He is currently an Editor of the KSII Transactions on Internet and Information Systems, an Editor of the International Journal of Internet of Things and Big Data, and an Associate Editor of the IEEE Communications Magazine. Current
Member of IEEE Communications Society. His research interests include Internet of Things and ubiquitous computing, big data, software defined networks, converged access networks, and 5G heterogeneous networks.

Olena Krasko is now an Assistant Professor of Telecommunications Department, Lviv Polytechnic National University, Lviv, Ukraine. She received her M.S. degree in information communication networks, Lviv Polytechnic National University, Ukraine in 2008, and BA degree in telecommunications, Lviv Polytechnic National University, Ukraine in 2007. She is currently an assistant with the Telecommunication department of Lviv Polytechnic National University. Her current research interests include optical access networks, IP over DWDM and software defined networks.

Maryan Kyryk is now an Associate Professor of Telecommunications Department, Lviv Polytechnic National University, Lviv, Ukraine. He received his BA from the Department of Telecommunication, Lviv Polytechnic National University in 1998, and a $\mathrm{PhD}$ in telecommunication systems and networks from Odessa National Academy of Telecommunications, Ukraine, in 2009. He has an experience in administration and management of the enterprise scale network. He worked as a software engineer in the Lviv Polytechnic IT Center. Currently he is the CEO of a telecommunication company that provides IPTV/OTT services on a metropolitan scale. His current research interests include distributed networks, software-defined networks, cloud computing, the IoT, quality of experience in IPTV/OTT, cognitive radio, and network resource management.

Vasyl Romanchuk is now a D. Sc. candidate with Telecommunications Department, Lviv Polytechnic National University, Lviv, Ukraine. He received his MS from the Department of Telecommunication, Lviv Polytechnic National University in 2003, and a PhD in telecommunication systems and networks from Odessa National Academy of Telecommunications, Ukraine, in 2008. He is working as a Deputy CEO of the in the Lviv Polytechnic Educational Center of Network Technologies. His current research interests include service oriented networks, software-defined networks, network functions virtualization, and network resource management.

Roman Kolodiy is now a Dean of the Institute of Telecommunications, Radio Electronics and Electronic Engineering, Lviv Polytechnic National University, Lviv, Ukraine. He received his MS from the Department of Radio Engineering, Lviv Polytechnic National University in 1994, and $\mathrm{a} \mathrm{PhD}$ in telecommunication systems and networks from Odessa National Academy of Telecommunications, Ukraine, in 2008. His current research interests include optical transport networks, switching systems, and softwaredefined networks. 